\title{
Photodynamic therapy: A mitochondrial inducer of apoptosis
}

\author{
David Kessel $^{1,2}$ and Yu Luo ${ }^{1}$ \\ ${ }^{1}$ Department of Pharmacology, Wayne State University School of Medicine, \\ Detroit, Michigan 48201, USA \\ 2 corresponding author: David Kessel, Department of Pharmacology, Wayne \\ State University School of Medicine, 540 E. Canfield Street, Detroit, Michigan \\ 48201, USA. tel: (313) 577 1766; fax: (313) 577 6739; \\ e-mail dhkessel@med.wayne.edu
}

Received 23.3.98; revised 27.5.98; accepted 10.8.98

Edited by D.Green

\begin{abstract}
Photodamage to the mitochondria of murine leukemia P388 cells resulted in immediate loss of the mitochondrial membrane potential together with the release of cytochrome $c$ into the cytosol. This was followed by a rapid activation of caspase 3-like proteases, as indicated by a marked rise in DEVDase activity. There was no significant effect on WEHDase or VEIDase activities, suggesting that only the late-stage caspases had been effected. The apoptotic response to mitochondrial photodamage was abolished by the broadspectrum caspase inhibitor ZVAD-fmk, but this did not prevent loss of viability after mitochondrial photodamage. These studies indicate that the release of cytochrome $c$ from photodamaged mitochondria is sufficient to directly initiate a caspase-dependent apoptotic response.
\end{abstract}

Keywords: apoptosis; photodynamic therapy; photosensitization; proteases

Abbreviations: Ac-DEVD-fmk, acetyl-asp-glu-val-asp fmk; amc, 7amino-4-methyl coumarin; cmk, chloromethylketone; CPO, 9capronyloxy-tetrakis(methyoxyethyl)porphycene; fmc, 7-amido-4trifluoromethyl coumarin; fmk, fluoromethylketone; FHS, Fischer's medium (10\% horse serum) buffered with 20 mM HEPES instead of $\mathrm{NaHCO}_{3}$; HO342, Höchst dye 33342 (bis-benzimide); PcM, porphycene monomer; $L_{\mathrm{xx}}$, PDT dose such that $\mathrm{xx} \%$ of the cells are killed; MTO, MitoTracker orange; NAO, nonyl acridine orange; PDT, photodynamic therapy; VEID, val-glu-ileu-asp; WEHD, trp-glu-his-asp; zVAD-fmk, z-val-ala-asp-fmk

\section{Introduction}

An important cell-death pathway involves the release of cytochrome c from mitochondria to the cytosol, thereby triggering caspase-3 activation, and initiation of the apoptotic program at a relatively late stage. ${ }^{1-3}$ Supporting evidence for this hypothesis was provided by experiments which established that microinjection of cytochrome $c$ into intact cells could induce an apoptotic response. ${ }^{4,5}$ The loss of mitochon- drial cytochrome $\mathrm{c}$ from cells stimulated to undergo apoptosis was associated with a loss of the mitochondrial membrane potential $\left(\triangle \Psi_{m}\right)$. While a mechanism for the initiation of the apoptotic program by cytosolic cytochrome $c$ has been described, ${ }^{6}$ the existence of other programmed cell death mechanisms is suggested by demonstrations of apoptosis without the appearance of cytosolic cytochrome $c,{ }^{7,8}$ and the failure of the microinjection procedure to initiate an apoptotic response in some cell lines. ${ }^{4}$

In this study, we examined factors relating to the initiation of a rapid apoptotic response by photodynamic therapy (PDT). PDT is an FDA-approved form of cancer therapy involving the somewhat selective photosensitization of neoplastic cells, usually with porphyrins or porphyrin-like drugs. The delivery of a suitable light dose to photosensitized tissues can result in a highly-localized eradication of neoplastic lesions ${ }^{9}$ with minimal damage to adjacent host tissues. Several groups have now reported that PDT can initiate a rapid apoptotic response. ${ }^{10-13}$ Rapid appearance of caspase-3 activity, along with PARP cleavage, has been reported after PDT in vitro. ${ }^{13-15}$ The mode of cell death (apoptosis vs necrosis) appears dependent on the cell line, the photosensitizing agent and the protocol. ${ }^{11,16,17}$ The critical determinants may relate to sites of sensitizer localization which may be a function of both the sensitizer and the cell type. We have reported that a supra lethal PDT dose can cause a necrotic response, as judged from the pattern of DNA fragmentation on agarose gels. ${ }^{15}$ The latter result may derive from photodamage to membranes, leading to leakage of cytosolic components, or from photodamage to caspases, cytochrome $\mathrm{c}$ and other components of the apoptotic process.

While some photosensitizing agents target multiple sub-cellular sites, agents with selective affinity for specific organelles can be used to produce highlylocalized photodamage. Because of the very short lifetime of singlet oxygen, the product formed by the photodynamic process, cytotoxicity subsequent to irradiation is confined to initial sites of drug localization. ${ }^{18}$

We have reported that an apoptotic response in murine leukemia cell lines occurs after mitochondrial photodamage, but not when mitochondria are spared and lysosomal and/or membrane sites are affected. ${ }^{19,20}$ In the current study, we employed two porphycenes which mediate mitochondrial photodamage while sparing lysosomes and the plasma membrane. The porphycenes represent a modification of the porphyrin structure with some advantageous photophysical properties. ${ }^{21}$ Initial studies were carried out with the porphycene monomer termed $\mathrm{PcM}^{20}$ but to insure that the results were not unique to a single drug, we have identified a second mitochondria-specific porphycene derivative (capronyloxy porphycene, CPO) described by Toledano et al. ${ }^{22}$ In this 
report, we provide information on the consequences of mitochondrial photodamage which result in the initiation of the apoptotic program. We also examined the effects of very high concentrations of these porphycenes in the dark, to provide an explanation for a previous observation that PcM can produce an apoptotic response under these conditions. ${ }^{20,23}$

\section{Results}

Results described here were mainly acquired using the porphycene PcM, but identical results were obtained with $\mathrm{CPO}$. All studies reported involved at least three repetitions of the experiments described, so that statistical interpretations were feasible. Murine leukemia P388 cells in culture were used throughout. Unless otherwise specified, conditions used in these experiments resulted in a $90 \%$ reduction of cell viability from photodynamic effects.

\section{Effects of photodamage on mitochondria, $\Delta \Psi_{m}$ and cytochrome c release}

Porphycene-induced photodamage resulted in an immediate loss of $\Delta \Psi_{\mathrm{m}}$, as detected by the fluorescent probe MTO, a marker for the mitochondrial membrane potential (Figure 1). Results obtained by fluorescence microscopy provide a qualitative evaluation of mitochondrial alterations with the results suggesting an 'all-or-none' phenomenon. Under conditions that resulted in a $92 \pm 5 \%$ loss of viability, less than $5 \%$ of the mitochondria retained the fibrillar fluorescence pattern observed with control cells. In these experiments, the incubation temperature never exceeded $10^{\circ} \mathrm{C}$ after irradiation, permitting delineation of the effects of photodamage on $\Delta \Psi_{\mathrm{m}}$ without the intervention of any temperature-sensitive step. Loss of the characteristic MTO labeling pattern is therefore a direct result of the photodynamic process. The nonyl acridine orange (NAO) labeling pattern remained unchanged after mitochondrial photodamage. This indicates that the organelle structure was preserved, since NAO labels mitochondria independent of $\Delta \Psi_{\mathrm{m}}{ }^{24}$ via an interaction with cardiolipin. ${ }^{25}$

Using Western blots, we demonstrated that cytochrome c was released into the cytosol immediately after the irradiation of porphycene-sensitized cells at $10^{\circ} \mathrm{C}$ (Figure 2). The control (lane A) provides an estimate of the extent of mitochondrial contamination and/or base-line mitochondrial damage in the cell extracts used in this assay. After PDT, the concentration of cytosolic cytochrome c continued to increase during a subsequent incubation at $37^{\circ} \mathrm{C}$, and was further enhanced by the presence of $100 \mathrm{nM}$ staurosporin, an agent which potentiated the apoptotic response to PDT.

\section{Dark toxicity of the porphycenes}

Under conditions employed in the PDT studies, the porphycenes did not initiate apoptosis in the absence of light, as indicated by the appearance of apoptotic nuclei detected by $\mathrm{HO} 342$ labeling. Exposure of cells for $15 \mathrm{~min}$ at $37^{\circ} \mathrm{C}$ to a $20 \mu \mathrm{M}$ concentration of either porphycene in the
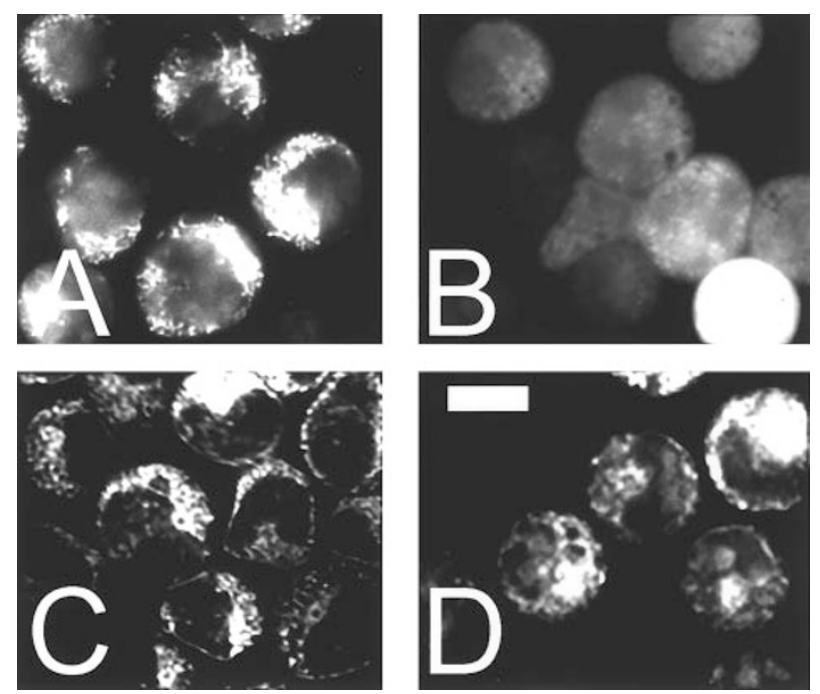

Figure 1 Effects of PDT (LD 90 conditions) on the mitochondrial membrane potential and structure using PcM: $(\mathbf{A})=$ MitoTracker orange labeling (control); (B)=MTO (after mitochondrial photodamage); (C)=nonyl acridine orange labeling (control); (D)=NAO (after mitochondrial photodamage). The extracellular porphycene concentration $=2 \mu \mathrm{M}$; after a 15 min loading incubation, cells were washed and irradiated with $4.5 \mathrm{~J} / \mathrm{cm}^{2}$ of light at $620 \pm 10 \mathrm{~nm}$. This corresponds to an LD 90 PDT dose. The white bar in panel $\mathrm{D}=10 \mu$

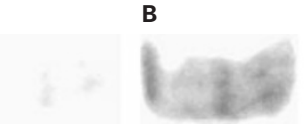

Figure 2 Western blot showing the level of cytosolic cytochrome $\mathrm{c}$ at various times after irradiation of photosensitized cells ( $L D_{90}$ conditions, sensitizer=PcM). From left: (A) control cytosol, (B) directly after PDT at $10^{\circ} \mathrm{C},(\mathbf{C})$ $10 \mathrm{~min}$ and (D) $30 \mathrm{~min}$ after a subsequent incubation at $37^{\circ} \mathrm{C}$, (E) $30 \mathrm{~min}$ after irradiation with $100 \mathrm{nM}$ staurosporin present during the porphycene-loading incubation

dark resulted in loss of the characteristic MTO labeling pattern (Figure 3) while the NAO labeling patterns remained unaffected (not shown). We also observed a time-dependent increase in DEVDase activity. Implications of these results are explored in the Discussion section.

\section{Caspase activation}

After irradiation of cells loaded with a $2 \mu \mathrm{M}$ concentration of either porphycene, subsequent incubation at $37^{\circ} \mathrm{C}$ resulted in a rapid increase in DEVDase activity which ultimately reached a peak value of $90 \mathrm{U} / \mathrm{mg}$ cells. There was no change in WEHDase or VEIDase activities (data obtained with PcM are shown in Figure 4A). Levels of WEHDase and VEIDase never deviated from baseline $(0.15 \pm 0.05 \mathrm{U} / \mathrm{mg}$ cells $)$. The broadspectrum caspase inhibitor zVAD-fmk $(10 \mu \mathrm{M})$, added during the porphycene-loading incubation, inhibited the increase of DEVDase activity after mitochondrial photodamage (Figure 4), and inhibited both chromatin and cellular fragmentation (Figure 5), but did not prevent the loss of $\Delta \Psi_{m}$ after PDT (Figure 6), nor was cell viability restored (Table 1). These 
results indicate that caspase activation is needed for the appearance of an apoptotic morphology, but not for the loss of $\Delta \Psi_{\mathrm{m}}$ which follows mitochondrial photodamage. The irreversible inhibition of caspase activation by zVAD-fmk did not, however, promote the viability of cells after an LD $_{50}$ PDT dose with either porphycene (Table 1).

Exposure of cells to $20 \mu \mathrm{M}$ levels of either porphycene also resulted in an increase in DEVDase activity (Figure 4B). In these studies, cell samples were periodically withdrawn during an incubation at $37^{\circ} \mathrm{C}$, washed free from the sensitizers and assayed for caspase activity.

\section{Effects of staurosporin on apoptosis and tyrosine phosphorylation}

A $100 \mathrm{nM}$ concentration of the protein kinase inhibitor staurosporin caused a marked potentiation of the apoptotic response to mitochondrial photodamage (Figure 7). This study was carried out using a light dose which reduced cell viability by approximately $50 \%$; addition of staurosporin promoted the cytotoxic effect (Table 1). The number of apoptotic cells $60 \mathrm{~min}$ after irradiation was increased from $38 \pm 4 \%$ to $67 \pm 5 \%$ when staurosporin was present, and there
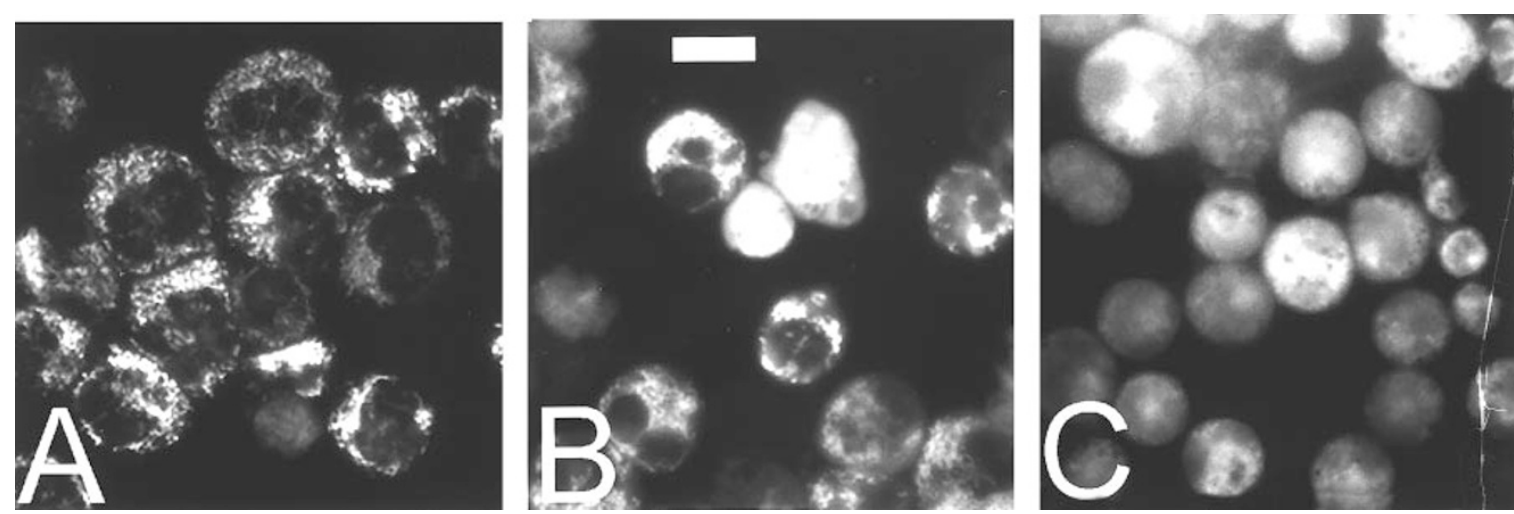

Figure 3 The loss of $\Delta \Psi_{\mathrm{m}}$ after a $15 \mathrm{~min}$ incubation with $20 \mu \mathrm{M}$ porphycene in the dark; this corresponds to a $90 \%$ loss of viability. (A)=controls, (B)=PcM, (C) $=\mathrm{CPO}$. The white bar in panel $\mathrm{B}=10 \mu$
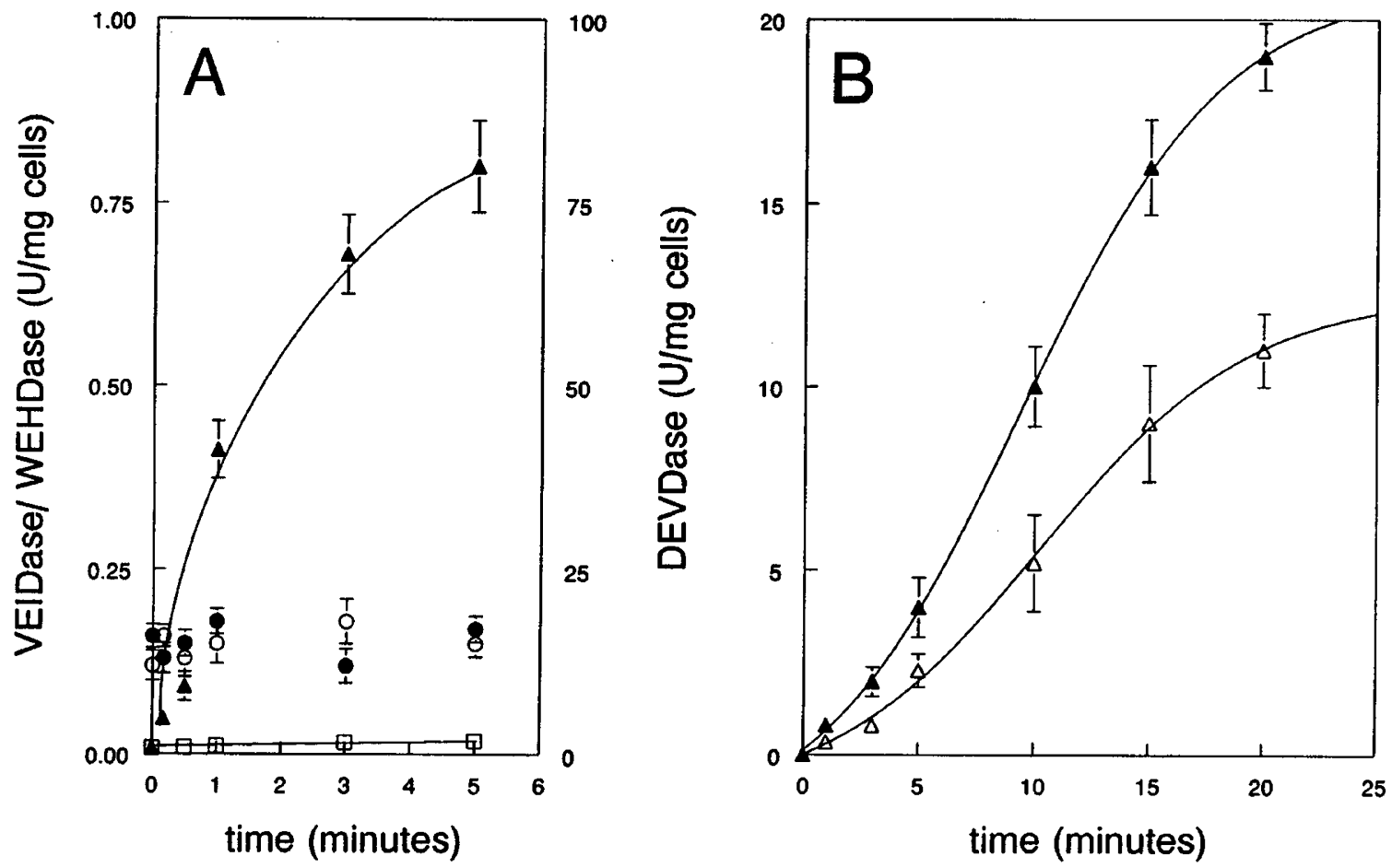

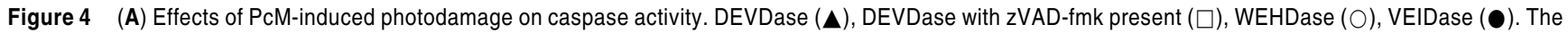
PDT dose is specified in the legend to Figure 1. (B) Promotion of DEVDase activity by incubation of cells with $20 \mu \mathrm{M}$ of $\mathrm{PcM}(\mathrm{O})$ or $\mathrm{CPO}(\boldsymbol{\bullet})$ in the dark for varying intervals 
was an increase in the rate of release of cytochrome $\mathrm{c}$ into the cytosol (Figure 2).

Exposure of P388 cells to $100 \mathrm{nM}$ staurosporin for 60 min did not result in the appearance of apoptotic cells, although prolonging the time to $24 \mathrm{~h}$ resulted in a $40-50 \%$
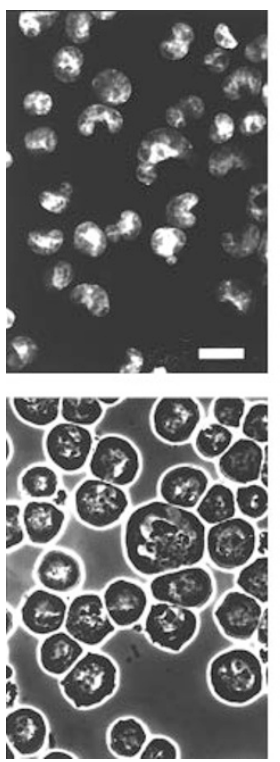

B
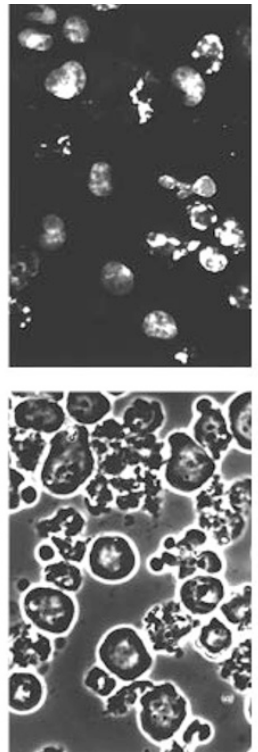

C
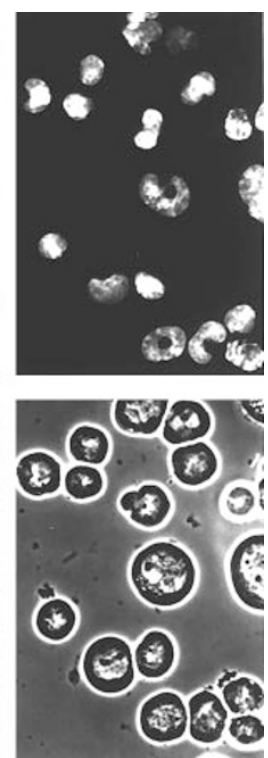

Figure 5 Effects of ZVAD-fmk on cell fragmentation and $\mathrm{HO} 42$ labeling of P388 cells after photodamage with $\mathrm{PcM}$. Ph=phase contrast images, $\mathrm{HO}=\mathrm{HO} 342$. From left: control cells (A), $60 \mathrm{~min}$ after PDT (B), $60 \mathrm{~min}$ after PDT in the presence of ZVAD-fmk (C). The PDT dose is defined in the legend to Figure 1. The white bar in panel $A=10 \mu$
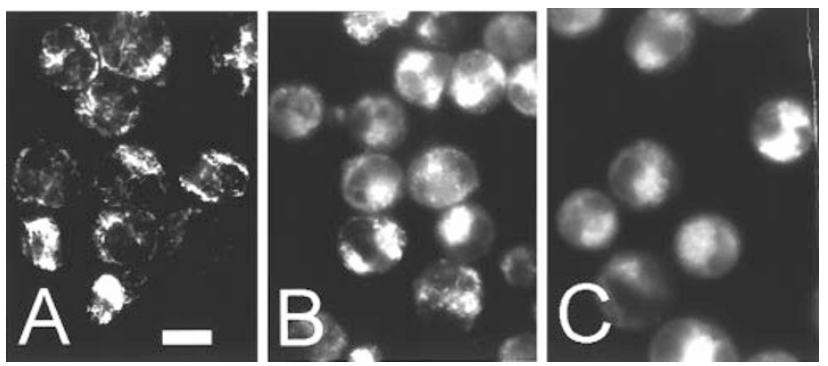

Figure 6 Effect of ZVAD-fmk on the MTO labeling pattern. $(\mathbf{A})=$ control cells, $(B)=$ cells directly after PDT at $10^{\circ} \mathrm{C},(\mathbf{C})=$ same as B with $10 \mu \mathrm{M}$ zVAD-fmk present. The PDT dose with PcM is defined in the legend to Figure 1. The white bar in panel $A=10 \mu$

Table 1 Effects of PDT on cell viability

\begin{tabular}{lrc}
\hline & PcM & CPO \\
\hline PDT $^{\text {a }}$ & $46 \pm 7$ & $53 \pm 4$ \\
PDT+zVAD-fmk & $43 \pm 5$ & $49 \pm 3$ \\
PDT+staurosporin $^{b}$ & $9 \pm 3$ & $17 \pm 3$ \\
Dark toxicity $^{\mathrm{c}}$ & $12 \pm 3$ & $14 \pm 4$ \\
\hline
\end{tabular}

Numbers reflect relative numbers of viable cells expressed as $\%$ control. ${ }^{a} \mathrm{LD}_{50}$ conditions: cells were loaded with $2 \mu \mathrm{M}$ porphycene, then irradiated $\left(1.5 \mathrm{~J} / \mathrm{cm}^{2}\right.$ at $620 \pm 10 \mathrm{~nm}$ ). ${ }^{\mathrm{b}} \mathrm{LD}_{50}$ PDT conditions with $100 \mathrm{nM}$ staurosporin present during the loading incubation. ${ }^{\mathrm{C}}$ Exposure of cells to $20 \mu \mathrm{M}$ porphycene for $15 \mathrm{~min}$ at $37^{\circ} \mathrm{C}$ in the dark (LD $\mathrm{LD}_{90}$ conditions) apoptotic population. These results indicate that the enhanced apoptotic response shown in Figure 7 is related to staurosporin-induced promotion of PDT-induced apoptosis.

The most prominent protein phosphorylation associated with PDT involves a tyrosine residue on a $75-80 \mathrm{kDa}$ protein which reaches a maximal level $30 \mathrm{~min}$ after irradiation (Figure 8). When $100 \mathrm{nM}$ staurosporin was present during the drug-loading incubation, the PDTassociated tyrosine phosphorylation was inhibited (Figure 8).

\section{Discussion}

In this report, we show that photodamage catalyzed by either of two porphycenes leads to loss of the mitochondrial membrane potential, release of cytochrome $c$ into the cytosol, a marked increase in DEVDase activity, cellular fragmentation and the appearance of apoptotic nuclei. The broad-spectrum caspase inhibitor zVAD-fmk ${ }^{26}$ abolished both apoptosis and the ensuing cell fragmentation (Figure 5), although the resulting loss of viability was not reversed. (Table 1). These results are interpreted to mean that cells which have had sufficient mitochondrial photodamage to abolish $\Delta \Psi_{\mathrm{m}}$ will ultimately die, although not via an apoptotic process. A similar phenomenon was reported by Lemaire et $a ;_{;}^{27}$ suppression of apoptosis by z-D-cmk or zVAD-fmk resulted in necrotic cell death.

The porphycenes used in this study are the most specific mitochondrial photosensitizing agents we have identified. Although we cannot yet exclude the possibility that these agents cause photodamage at additional subcellular loci, studies with a series of fluorescent probes indicate that neither $\mathrm{PCM}^{20}$ nor CPO (unpublished) target lysosomes or the cell membrane. We had previously reported that apoptosis can be induced by agents that target mitochondria or mitochondria and lysosomes, but not after membrane or lysosomal photodamage. ${ }^{20}$

A unique property of PDT is that photodamage does not occur until photosensitized cells are irradiated. When irradiation occurs at reduced temperatures, effects of photodamage can be observed in the absence of subsequent enzymatic reactions. The immediate loss of $\Delta \Psi_{\mathrm{m}}$ (Figure 1) is interpreted to reflect a direct consequence of mitochondrial photodamage. These results are consistent with reports implicating the mitochondrion as a source of factors which initiate an apoptotic response. 1,2,28,29 Since mitochondrial photodamage results in a prompt loss of $\Delta \Psi_{\mathrm{m}}$, the apoptogenic effects of PDT are not necessarily comparable to those from other stimuli, where the loss of $\Delta \Psi_{\mathrm{m}}$ can occur after the release of cytochrome $c$ into the cytosol. ${ }^{30}$ The altered MTO labeling pattern that occurs when cells are maintained at $10^{\circ} \mathrm{C}$ during and after irradiation (Figure 1) make it unlikely that protease activation plays a role in the loss of $\Delta \Psi_{\mathrm{m}}$.

We had previously shown that PDT with the sensitizer aluminum phthalocyanine initiated PARP cleavage within $10 \mathrm{~min}$, an effect which suggests rapid caspase activation. A more direct proof is provided here, using a fluorogenic 

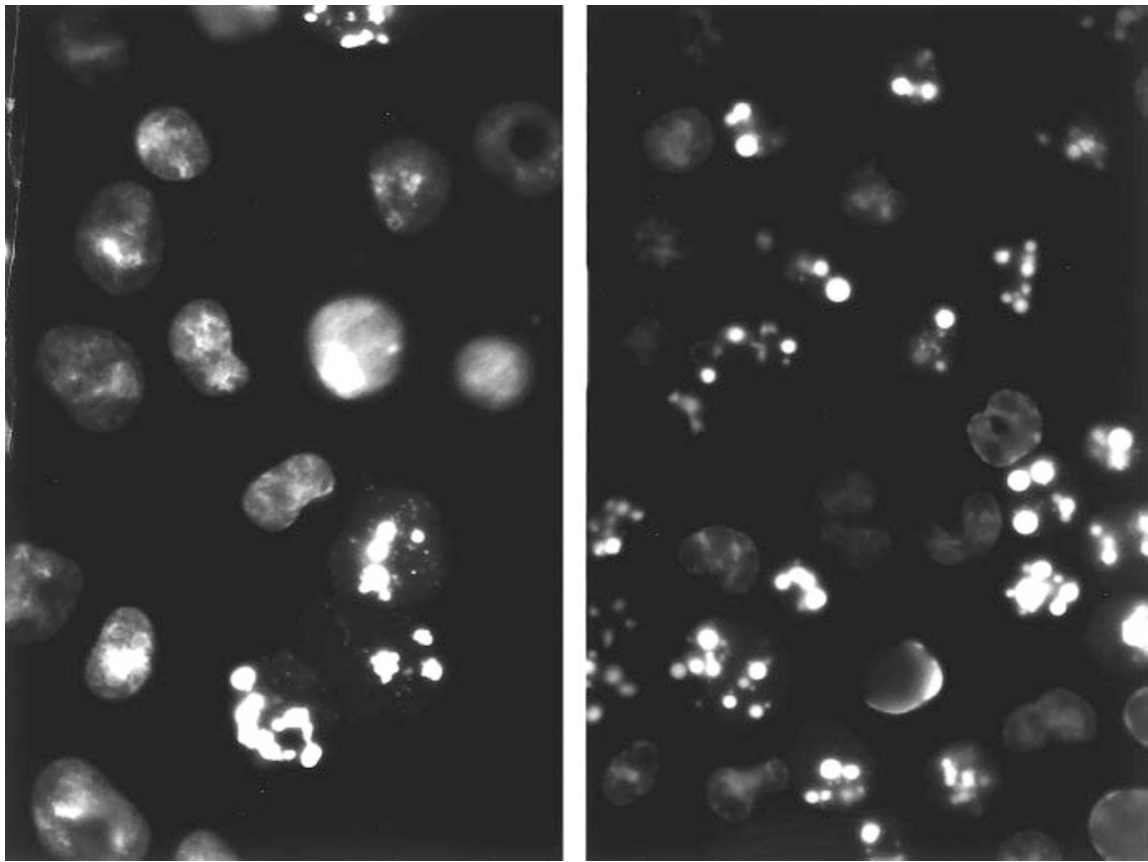

Figure $7 \mathrm{HO} 342$ labeling of cells $60 \mathrm{~min}$ after an $\mathrm{LD}_{50}$ PDT dose, using PcM. Left: no additions, right: $100 \mathrm{nM}$ staurosporin was present during the porphyceneloading incubation. The light dose was $1.5 \mathrm{~J} / \mathrm{cm}^{2}$ at $620 \pm 10 \mathrm{~nm}$

A

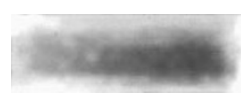

B

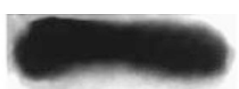

C

Figure 8 Protein tyrosine phosphorylation: (A) control cells; (B) 30 min after mitochondrial photodamage initiated by $\mathrm{PcM}$ ( $\mathrm{LD}_{90}$ conditions); (C) inhibition of PDT-induced phosphorylation by the presence of $100 \mathrm{nM}$ staurosporin during the porphycene-loading incubation

tetrapeptide substrate optimized for caspase 3-like proteases. $^{31}$

The release of cytochrome c after irradiation (Figure 2) was sufficient to initiate a rapid increase in DEVDase activity (Figure 4). Other demonstrations of rapid caspase activation after PDT have been reported. ${ }^{13,14}$ In an earlier report, Enari et $a^{32}$ utilized two fluorogenic tetrapeptide caspase substrates to explore the sequence of activation of caspase- 1 and -3 . In the present study, we similarly used WEHD-amc, an optimal or near-optimal substrate for caspases 1, 4 and 5, and VEID-amc, a substrate for caspase- 6 and $-8 .^{31}$ The lack of activity above control values suggests that these proteases are not activated after mitochondrial photodamage, assuming that these substrates will detect the activity of the respective caspases. In a study involving HL-60 cells and a different photosensitizing agent, ${ }^{13}$ also detected activation of caspase-3 but not caspase-1.

At a $100 \mathrm{nM}$ level, the protein kinase inhibitor staurosporin markedly promoted the apoptotic response to mitochondrial photodamage (Figure 7, Table 1), as well as release of cytochrome $c$ from mitochondria (Figure 2). This was accompanied by inhibition of the PDT-induced phosphorylation of a tyrosine residue on an $\sim 80 \mathrm{kDa}$ protein (Figure 8). This protein was identified as HS1 by Xue et $a l^{33}$ and it was postulated that enhanced phosphorylation of this protein might serve to protect cells from the lethal effects of PDT. The results described here are consistent with this hypothesis: inhibition of HS1 phosphorylation was associated with an enhanced apoptotic response. Although there have been reports that PDT can initiate other signal-transduction events, ${ }^{17}$ we propose that the release of mitochondrial cytochrome $c$ alone is sufficient for the triggering of an apoptotic response. Granville et $a l^{34}$ recently reported a similar effect of staurosporin; PDT-induced phosphorylation of a $>200 \mathrm{kDa}$ protein was inhibited by a significantly higher (3.2 $\mu \mathrm{M})$ level of staurosporin. These studies were carried out with the P815 mouse leukemia and a different sensitizer. Unlike results reported here, only a slight promotion of the apoptotic effects of PDT resulted from this high-dose of staurosporin.

Earlier studies indicated that exposure of P388 cells to a $20 \mu \mathrm{M}$ extracellular porphycene concentration resulted in the initiation of apoptosis in the dark. ${ }^{20,23}$ At this drug concentration, 20-fold higher than the level used to catalyze photodamage, we observed a fall in $\Delta \Psi_{\mathrm{m}}$ (Figure 3), along with transfer of cytochrome to the cytosol (not shown) and promotion of DEVDase activity (Figure 4B). The latter effect resulted in a sigmoidal curve, resulting from the autocatalytic effect of a gradual release of cytochrome $\mathrm{c}$ as mitochondrial damage proceeds. In contrast, the increase in DEVDase activity after photodamage to a substantial number of mitochondria was more rapid and lacked the 'lag' phase (Figure 4A). It is interesting to note that protoporphyrin, a photosensitizing agent that binds to the mitochondrial peripheral benzodia- 
zepine receptor, also causes a 'dark' mitochondrial permeability transition. ${ }^{35,36}$ Henderson et al ${ }^{37}$ recently examined a series of porphyrin analogs and reported that the most potent of these showed a strong affinity for a site on albumin that also binds benzodiazepine receptor antagonists. ${ }^{38}$ These results suggest that the affinity of certain photosensitizing agents for the peripheral benzodiazepine receptor may account for the targeting of mitochondria for photodamage.

Ellerby et $a^{39}$ have proposed three mechanisms for the initiation of apoptosis: Pre-mitochondrial inducers, e.g., tamoxifen, can initiate a signal transduction cascade resulting in release of mitochondrial factors which initiate apoptosis. This class of agents includes most common anti-tumor agents and perhaps ionizing radiation; Mitochondrial inducers, e.g., atractyloside, although nonpermeable, can act directly on isolated mitochondria to yield apoptosis-inducing factors; Post-mitochondrial inducers, represented by cytochrome $\mathrm{c}$, initiate apoptosis in a cell-free system lacking mitochondria. Hickman et al ${ }^{40}$ and Fearnhead et $a l^{41}$ proposed that the apoptotic program is present in drug-resistant cell lines, with the pathway to apoptosis often inhibited by mutations which suppress apoptotic signals. Since mitochondrial perturbations sufficient to cause a release of cytochrome $c$ can trigger apoptosis, mitochondria have been proposed as a potential target for cancer therapy ${ }^{42}$ thereby providing a direct stimulus to apoptotic cell death. Using Ellerby's criteria, we propose that these porphycenes can be classified as 'permeable' mitochondrial inducers of apoptosis. The broad spectrum of tumor responses to $\mathrm{PDT}^{9}$ would then result from the initiation of apoptosis at such a late stage that impaired signal transduction pathways are bypassed.

\section{Materials and Methods}

\section{Cells and cell culture}

Murine leukemia P388 cells were maintained in Fischer's medium (Gibco-BRL) supplemented with gentamicin, glutamine, and $10 \%$ horse serum. Cells were collected by centrifugation during the exponential period of growth. The wet weight of the cell pellet was determined, and the cells were then resuspended in growth medium (buffered with $20 \mathrm{mM} \mathrm{HEPES}$ at $\mathrm{pH}$ 7.2) at a density of $7 \mathrm{mg} / \mathrm{ml}$.

\section{Chemicals}

DEVD-amc, WEHD-amc, DEVD-fmk and zVAD-fmk were purchased from Enzyme Systems Products, Livermore, CA, USA. Two porphycenes were used for mitochondrial photosensitization, $\mathrm{PcM}^{23}$ and $\mathrm{CPO}^{22}$. Fluorescent dyes (MTO, NAO and HO342) were provided by Molecular Probes, Eugene, OR, USA.

\section{Incubation and irradiation}

Cell suspensions were incubated with PcM or CPO porphycenes (final concentration $=2 \mu \mathrm{M}$ ) for $15 \mathrm{~min}$ at $37^{\circ} \mathrm{C}$, collected by centrifugation and suspended in fresh medium. Where specified, $10 \mu \mathrm{M}$ zVAD-fmk was present during the initial incubation. In some experiments, MTO or
NAO $(10 \mu \mathrm{g} / \mathrm{ml})$ was present during the loading incubation. Irradiation was carried out at $10^{\circ} \mathrm{C}$ to minimize temperature-dependent metabolic processes.

The light source was a 600 watt quartz-halogen lamp with the output filtered through a $10 \mathrm{~cm}$ layer of water to remove wavelengths $>900 \mathrm{~nm}$. The bandwidth was further limited by a heat-absorbing filter (bandpass $=400-850 \mathrm{~nm}$ ) and an interference filter $(620 \pm 10 \mathrm{~nm})$. The light dose was adjusted to decrease viability of photosensitized cells to $50 \%$ of controls $\left(1.5 \mathrm{~J} / \mathrm{cm}^{2}\right)$, or to $10 \%$ of control $\left(4.5 \mathrm{~J} / \mathrm{cm}^{2}\right)$. The light flux was measured with a calibrated EG\&G model 450 radiometer. After irradiation, the cells were treated as described below. Cell viability was determined by clonogenic assays (plating efficiency $>80 \%$ ). In some experiments, we assessed the dark toxicity resulting from a 15 min incubation at $37^{\circ} \mathrm{C}$ using $20 \mu \mathrm{M}$ levels of the porphycenes. The cells were never exposed to light, but immediately used for further experiments as outlined below.

\section{Fluorescence microscopy}

Direct effects of irradiation on the mitochondrial membrane potential $\Delta \Psi_{\mathrm{m}}$ were determined by labeling with MTO $(10 \mu \mathrm{g} / \mathrm{ml})$. Mitochondrial damage was assessed with the probe NAO $(10 \mu \mathrm{g} / \mathrm{ml})$. To eliminate the need for warming the cells after irradiation, these probes were added during the first incubation. Effects of mitochondrial photodamage on $\Delta \Psi_{\mathrm{m}}$ could thereby be assessed on cells that were at no time exposed to temperatures $>10^{\circ} \mathrm{C}$ during or after irradiation. MTO fluorescence $(580-620 \mathrm{~nm})$ was detected upon excitation at $510-$ $560 \mathrm{~nm}$. NAO fluorescence was determined using excitation at $470-$ $500 \mathrm{~nm}$ and measuring emission at 515-530 nm. A $600 \mathrm{~nm}$ low-pass filter was inserted into the excitation path to minimize transmission of IR to the CCD camera.

For the detection of apoptotic nuclei, cells were diluted to a density of $4 \times 10^{5} / \mathrm{ml}$ after irradiation, and incubated at $37^{\circ} \mathrm{C}$, usually for $60 \mathrm{~min}$. The cells were then collected and labeled with MTO+HO342 $(2 \mu \mathrm{g} / \mathrm{ml})$. After $5 \mathrm{~min}$ at $37^{\circ} \mathrm{C}$, the cells were collected by centrifugation and the percentage of apoptotic nuclei were determined by fluorescence microscopy (three fields of 100 cells each). HO342 fluorescence $(420-450 \mathrm{~nm})$ was detected upon excitation at $330-380 \mathrm{~nm}$. There was no crossover between $\mathrm{HO} 342$ and MTO fluorescence under these conditions. All fluorescence studies were carried out using a Nikon Labophot microscope fitted with a digital CCD camera (Photometrics, Tucson, AZ, USA). A $600 \mathrm{~nm}$ low-pass filter was inserted into both the excitation path and the CCD camera entry port to reduce transmission of infra-red light from the mercury source which will otherwise fog the CCD detector, Images were processed with MetaMorph software (Universal Imaging Corp., West Chester, PA, USA).

\section{Caspase assays}

Cell pellets $\left(2 \times 10^{6}\right.$ cells $)$ were collected at intervals after incubation at $37^{\circ} \mathrm{C}$ following irradiation and lysed in $50 \mathrm{mM}$ Tris buffer $\mathrm{pH} 7.5$ containing $0.03 \%$ Nonidet and $1 \mathrm{mM}$ DTT. Nuclei were removed by low-speed centrifugation $(800 \times g, 5 \mathrm{~min})$ and the cytosol fraction was incubated with $40 \mu \mathrm{M}$ DEVD-amc, WEHD-fmc or VEID amc, $10 \mathrm{mM}$ HEPES pH 7.5, $50 \mathrm{mM} \mathrm{NaCl}$ and $2.5 \mathrm{mM}$ DTT in a total volume of $200 \mu \mathrm{l}$ for $120 \mathrm{~min}$ at $37^{\circ} \mathrm{C}$. Coumarin fluorescence, released by caspase activity, was measured using $360 \mathrm{~nm}$ excitation. Effects of porphycenes in the dark were determined using $20 \mu \mathrm{M}$ drug levels. Cells were collected at intervals, washed free from extracellular drug, and the assay was carried out as defined above. A CCD device 
(Instaspec IV, Oriel, Statford, CT, USA) fitted with a monochromator was used to measure the fluorescence emission spectrum. The intensity at the optimum (approximately $450 \mathrm{~nm}$ ) was measured. Units of enzyme activity are defined in terms of pmols of substrate hydrolyzed $/ \mathrm{mg}$ cells $/ \mathrm{mg}$ protein/60 $\mathrm{min}$. In all cases, blank determinations were made (no cells, or cells without PDT). The system was initially calibrated with known levels of aminomethyl- or trifluoromethylcoumarin.

\section{Effect of staurosporin on PDT-induced apoptosis}

The photosensitizer loading incubation was carried out with both sensitizer and $100 \mathrm{nM}$ staurosporin or $10 \mu \mathrm{M}$ zVAD-fmk, for $15 \mathrm{~min}$ at $37^{\circ} \mathrm{C}$. The cells were then suspended in fresh medium, irradiated and incubated in fresh medium for $60 \mathrm{~min}$ at $37^{\circ} \mathrm{C}$ then labeled with $\mathrm{HO} 342$ as described above. To assess both apoptosis and cell fragmentation, we also acquired phase-contrast images of the same fields.

\section{Western blots for cytochrome $\mathrm{c}$ and phosphotyrosine}

Release of cytochrome c from mitochondria was assessed using control cells and cells collected at intervals during a second incubation at $37^{\circ} \mathrm{C}$ following irradiation, using $\mathrm{PcM}$ or $\mathrm{CPO}$. Pellets were collected and gently homogenized in buffer containing sucrose, with nuclei and mitochondria removed by centrifugation. $^{2}$ The resulting cytosolic preparations were analyzed on $15 \%$ gels and the presence of cytochrome $c$ determined using an anti-cytochrome $c$ MAb described by Jemmerson et al. $^{43}$ Phosphotyrosine residues were detected by a similar procedure. The procedure was based on the method used by Kanakura et al. ${ }^{44}$ Cells were incubated for $20 \mathrm{~min}$ at $4^{\circ} \mathrm{C}$ in a Tris-based lysis buffer containing $\mathrm{NaCl}$, glycerol, $1 \%$ Nonidet P-40, $10 \mathrm{mM}$ EDTA, and several protease inhibitors, along with $\mathrm{NaF}$ and the tyrosine phosphatase inhibitor sodium orthovanadate. A mixture of three phosphotyrosine probes was used (Zymed Labs, South San Francisco, CA, USA): PY-7EI, PY-1B2 \& PY20. After immunoblotting, the remaining binding sites on the filter were blocked by treatment with fat-free milk (MLK), and the PVDF membrane incubated overnight with antibody in TBS buffer containing MLK, washed and incubated in TBS-MLK buffer containing goat anti-mouse IgG linked to alkaline phosphatase. Gel images were visualized by a fluorogenic procedure using the Molecular Dynamics 'STORM' imaging system.

\section{References}

1. Kluck RM, Bossy-Wetzel E, Greene DR and Newmeyer DW (1997a) The release of cytochrome $\mathrm{C}$ from mitochondria: a primary site of $\mathrm{Bcl}-2$ regulation of apoptosis. Science 275: 1132-1136

2. Liu X, Kim CN, Jemmerson R and Wang X (1996) Induction of apoptotic program in cell-free extracts: requirement for dATP and cytochrome c. Cell 86: 147-157

3. Yang J, Bhalla K, Kim CN, Ibrado AM, Peng TI, Jones DP and Wang X (1997) Prevention of apoptosis by $\mathrm{Bcl}-2$ : release of cytochrome $\mathrm{c}$ from mitochondria blocked. Science 275: 1129-1132

4. Li F, Srinivasan A, Wang Y, Armstrong RC, Tomaselli KJ and Fritz LC (1997) Cell-specific induction of apoptosis by microinjection of cytochrome c. Bcl-xL has activity independent of cytochrome $c$ release. J. Biol. Chem. 272: 30299-30305
5. Zhivotovsky B, Orrenius S, Brustugun OT and Døskeland SO (1998) Injected cytochrome $c$ induces apoptosis. Nature 391: 449-450

6. Zou H, Henzel WJ, Liu X, Lutschg A and Wang X (1997) Apaf-1, a human protein homologous to $\mathrm{C}$. elegans CED-4, participates in cytochrome c-dependent activation of caspase-3. Cell 90: 405-413

7. Cauhan D, Pandey P, Ogata A, Teoh G, Krett N, Halgren R, Rosen S, Kufe D, Kharbanda D and Anderson K (1997) Cytochrome c-dependent and -independent induction of apoptosis in multiple myeloma cells. J Biol Chem. 272: 29995-29997

8. Tang DG, Li L and Joshi B (1998) Apoptosis in the absence of cytochrome c accumulation in the cytosol. Biochem. Biophys. Res. Commun. 242: 380-384

9. Schuitmaker JJ, Baas P, van Leengoed HL, van der Meulen FW, Star WM, van Zandwijk N (1996) Photodynamic therapy: a promising new modality for the treatment of cancer. J. Photochem. Photobiol. B. Biol. 34: 3-12

10. Agarwal ML, Clay ME, Harvey EJ, Evans HH, Antunez AR, Oleinick NL (1991) Photodynamic therapy induces rapid cell death by apoptosis in L5178Y mouse lymphoma cells Cancer Res. 51: 5993-5996

11. HeX-Y, Sikes R, Thomsen S, Chung LWK and Jacques SL (1994) Photodynamic therapy with photofrin II induces programmed cell death in carcinoma cell lines. Photochem. Photobiol. 59: 468-473

12. Luo Y, Chang CK and Kessel D (1996) Rapid initiation of apoptosis by photodynamic therapy. Photochem. Photobiol. 63: 528-534

13. Granville DJ, Levy JG and Hunt DWC (1997) Photodynamic therapy induces caspase-3 activation in HL-60 cells. Cell Death Differ. 4: 623-628

14. He J, Whitacre CM, Xue LY, Berger NA and Oleinick NL (1998) Protease activation and cleavage of poly(ADP-ribose) polymerase: an integral part of apoptosis response to photodynamic therapy. Cancer Res. 58: 940-946

15. Luo Y and Kessel D (1997) Initiation of apoptosis vs. necrosis by photodynamic therapy with chloroaluminum phthalocyanine. Photochem. Photobiol. 66: 479483

16. Dellinger M (1996) Apoptosis or necrosis following photofrin photosensitization: influence of the incubation protocol. Photochem. Photobiol. 64: $182-187$

17. Oleinick NL, Agarwal ML, Berger NA, Berger S, Cheng MF, Chattered S, He J, Kenney ME, Larkin HE, Mukhtar H, Rihter BD and Zaidi SIA (1993) Signal transduction and metabolic changes during tumor apoptosis following phthalocyanine-sensitized photodynamic therapy. Proc. SPIE. 1881: 252-261

18. Moan J and Berg K (1991) The photodegradation of porphyrins in cells can be used to estimate the lifetime of singlet oxygen. Photochem. Photobiol. 53: 549553

19. Kessel D, Luo Y, Deng $Y$ and Chang CK (1997) The role of sub-cellular localization in initiation of apoptosis by photodynamic therapy. Photochem. Photobiol. 65: 422-426

20. Kessel D and Luo Y (1998) Mitochondrial photodamage and PDT-induced apoptosis. J Photochem. Photobiol. B. Biol. 42: 89-95

21. Braslavsky SE, Müller M, Mártire DO, Pörting S, Bertolotti SG, Chakravorti S, Koc-Weier G, Knipp B and Schaffner K (1997) Photophysical properties of porphycene derivatives ( $18 \pi$ porphyrinoids) JPhotochem. Photobiol. B: Biol. 49 : 191-198

22. Toledano, Edrai R and Kimel S (1998) Photodynamic damage by liposomebound porphycenes: comparison between in vitro and in vivo models. J. Photochem. Photobiol: B. Biol. 42: 20-27

23. Kessel D, Luo Y, Woodburn K, Chang CK and Henderson BW (1995) Mechanisms of phototoxicity catalyzed by two porphycenes. Proc. SPIE 2392: $122-128$

24. Kunz-SchughartLA, HabbersettRC and FreyerJP (1997) Mitochondrial function in oncogene-transfected rat fibroblasts isolated from multicellular spheroids. Am. J. Physiol. 273: C1487-C1495

25. Petit JM, Maftah A, Ratinaud MH and Julien R (1992) 10N-nonyl acridine orange interacts with cardiolipin and allows the quantification of this phospholipid in isolated mitochondria. Eur. J. Biochem. 209: 267-273

26. Slee EA, Zhu H, Chow SC, MacFarlane M, Nicholson DW and Cohen GME (1996) Benzyloxycarbonyl-Val-Ala-Asp (OMe) fluoromethylketone (ZVAD.FMK) inhibits apoptosis by blocking the processing of CPP32. Biochem. J. 315: 21-24

27. Lemaire C, Andreau K, Souvannavong V, Adam A. (1998) Inhibition of caspase activity induces a switch from apoptosis to necrosis. FEBS Lett. 425: 266-270 
28. Kluck RM, Martin SJ, Hoffman BM, Zhou JS, Green DR and Newmeyer DD (1997b) Cytochrome c activation of CPP32-like proteolysis plays a critical role in a Xenopus cell-free apoptosis system. EMBO J. 16: 4639-4649

29. Susin SA, Zamzami N, Castedo M, Daugas E, Hong-Gang W, Geley S, Fassy F, Reed JC and Kroemer G. (1997) The central executioner of apoptosis: multiple connections between protease activation and mitochondria in Fas/APO-1/ DC95- and ceramide-induced apoptosis. J. Exp. Med. 186: 25-37

30. Bossy-Wetzel E, NewmeyerDD and Green DR (1998) Mitochondrial cytochrome c release occurs upstream of DECD-specific caspase activation and independently of mitochondrial transmembrane depolarization. EMBO J. 17: $37-49$

31. Thornberry NA, Rano TA, Peterson EP, Rasper DM, Timkey T, Garcia-Calvo M, Houtzager VM, Nordstrom PA, Roy S, Vaillancourt JP, Chapman KT and Nicholson DW (1997) A combinatorial approach defines specificities of members of the caspase family and granzyme B. J. Biol. Chem. 272: 17907-17911

32. Enari M, Talanian RV, Wong WW and Nagata S (1996) Sequential activation of ICE-like and CPP32-like proteases during Fas-mediated apoptosis. Nature 380: $723-726$

33. Xue LY, He J and Oleinick NL (1997) Rapid tyrosine phosphorylation of HS1 in the response of mouse lymphoma L5178Y-R cells to photodynamic treatment sensitized by the phthalocyanine Pc 4. Photochem. Photobiol. 66: $105-113$

34. Granville DJ, Levy JG and Hunt DWC (1998) Photodynamic treatment with benzoporphyrin derivative monoacid ring A produces protein tyrosine events and DNA fragmentation in murine P815 cells. Photochem. Photobiol. 67: 358-362

35. Pastorino JG, Simbula G, Gilfor E, Hoek JB, Farber JL (1994) Protoporphyrin IX, an endogenous ligand of the peripheral benzodiazepine receptor, potentiates induction of the mitochondrial permeability transition and the killing of cultured hepatocytes by rotenone. J. Biol. Chem. 269: 31041-31046

36. Ratcliffe SL and Matthews EK (1995) Modification of the photodynamic action of delta-aminolaevulinic acid (ALA) on rat pancreatoma cells by mitochondrial benzodiazepine receptor ligands. Br. J. Cancer 71: 300-305
37. Henderson BW, Bellnier DA, Greco WR, Sharma A, Pandey RK, Vaughan LA, Weishaupt KR and Dougherty TJ (1997) An in vivo quantitative structure-activity relationship for a congeneric series of pyropheophorbide derivatives as photosensitizers for photodynamic therapy. Cancer Res. 57: 4000-4007

38. Tsuchida T, Zheng G, Pandey RK, Potter WR, Bellnier DA, Henderson BW, Kato $\mathrm{H}$ and Dougherty TJ (1997) Correlation between site II specific human serum albumin (HSA) binding affinity and in vivo photosensitizing efficacy of some photofrin components. Photochem. Photobiol. 66: 224-229

39. Ellerby HM, Martin SJ, Ellerby LM, Naiem SS, Rabizadeh S, Salvesen GS, Casiano CA, Cashman NR, Green DRand Bredesen DE (1997) Establishment of a cell-free system of neuronal apoptosis: comparison of premitochondrial, mitochondrial and postmitochondrial phases. J. Neurosci. 17: 6165-6178

40. Hickman JA, Potten CS, Merritt AJ and Fisher TC (1994) Apoptosis and cancer chemotherapy. Phil. Trans. R. Soc. Lond. B 345: 319-325

41. Fearnhead HO, McCurrach ME, O'Neal J, Zhang K, Lowe SW and Lazebnik YA. (1997) Oncogene-dependent apoptosis in extracts from drug-resistant cells. Genes Dev. 11: 1266-1276

42. Decaudin D, Marzo I, Brenner C and Kroemer G (1998) Mitochondria in chemotherapy-induced apoptosis: a prospective novel target of cancer therapy. Int. J. Oncol. 12: 141-152

43. Jemmerson R, Johnson JH, Burrell E, Taylor PS and Jenkins MK (1991) A monoclonal antibody specific for a cytochrome C T-cell stimulatory peptide inhibits I cell responses and affects the way the peptide associates with antigenpreserving cells. Eur. J. Immunol. 21: 143-151

44. Kanakura Y, Druker B, DiCarlo J, Cannistra SA and Griffin JD (1991) Phorbol 12 myristate 13-acetate inhibits granulocyte-macrophage colony stimulating factorinduced protein tyrosine phosphorylation in a human factor-dependent hematopoietic cell line. J. Biol. Chem. 266: 490-495 